\title{
Efficacy Of Line Probe Assay In Detection Of Drug-Resistant Pulmonary Tuberculosis In Comparison With GeneXpert And Phenotypic Methods In Iran And Genetic Analysis Of Isolates By MIRU-VNTR
}

This article was published in the following Dove Press journal: Infection and Drug Resistance

\begin{abstract}
Hossein Kazemian'
Jalil Kardan-Yamchi

Abbas Bahador (iD)

Shadi Khonsari ${ }^{3}$

Mahshid Nasehi iD ${ }^{4}$

Gholamreza Hamzehloo ${ }^{5}$

Farzam Vaziri ${ }^{6}$

Mohammad Reza Salehi (iD ${ }^{7}$

Mohammad Mehdi

Feizabadi (D) ${ }^{1,8}$

'Department of Medical Microbiology, School of Medicine, Tehran University of Medical Sciences, Tehran, Iran; ${ }^{2}$ Division of Microbiology, Department of Pathobiology, School of Public Health, Tehran University of Medical Sciences, Tehran, Iran; ${ }^{3}$ Natural

Science Department, School of Science and Technology, Middlesex University, London, UK; ${ }^{4}$ Department of Epidemiology and Biostatistics, Iran University of Medical Sciences, Tehran, Iran; ${ }^{5}$ Tehran Regional Reference Laboratory for Tuberculosis, Tehran, Iran; ${ }^{6}$ Department of

Mycobacteriology and Pulmonary Research, Pasteur Institute of Iran, Tehran, Iran;

${ }^{7}$ Department of Infectious Disease, Imam Khomeini Hospital, Tehran University of Medical Sciences, Tehran, Iran; ${ }^{8}$ Thoracic Research Center, Imam Khomeini Hospital, Tehran University of Medical Sciences,

Tehran, Iran
\end{abstract}

Correspondence: Mohammad Mehdi Feizabadi

Department of Medical Microbiology, School of Medicine, Tehran University of

Medical Sciences, Poursina Street,

Engelab-e-Eslami Avenue, Tehran, Iran

Tel +989/21767987

Fax +982188955810

Email mfeizabadi@tums.ac.ir
Background: Successful treatment of tuberculosis depends on early diagnosis and use of appropriate drug susceptibility testing in a timely manner. In the present study, LPA efficacy was assayed in detection and drug susceptibility testing of pulmonary tuberculosis in comparison to available methods in Iran and phylogenetic analyses of isolated cases carried out by MIRU-VNTR.

Methods: This study was conducted at the Tehran Regional Reference Laboratory for Tuberculosis. All sputum specimens were subjected to smear, culture, and drug susceptibility testing (DST), GeneXpert, and LPA. Finally, 15-locus-based MIRU-VNTR was used for molecular genotyping.

Results: From a total of 920 sputum specimens, $6.08 \%(n=56)$ were identified as MTBC by culture, $6.8 \%(\mathrm{n}=63)$ by GeneXpert, and $6.5 \%(\mathrm{n}=60)$ by LPA. Phenotype DST and LPA methods confirmed the resistance of 4 and 14 specimens to rifampin (RIF) and isoniazid (INH); two cases were considered as multidrug-resistant (MDR). Using GeneXpert, four cases were identified as RIF-resistant. Based on LPA results, inhA and kat G mutations were detected in $100 \%$ and $21.4 \%$ of INH-resistant cases, respectively. All 56 culture positive Mycobacterium tuberculosis isolates were placed in 29 different clusters using MIRU-VNTR genotyping. Two MDR-TB, 2 RIF mono-resistant, and 12 INH mono-resistant cases were placed in different clusters.

Conclusion: LPA is an appropriate method for early detection and accurate diagnosis of TB and drug-resistant cases that makes it possible to distinguish INH mono-resistant cases from MDR cases in Iran.

Keywords: tuberculosis, line probe assay, early diagnosis, drug resistance, mutation

\section{Introduction}

The causative agent of tuberculosis is Mycobacterium tuberculosis, which can acquire resistance to the first-line anti-TB drugs, rifampin (RIF), and isoniazid (INH). Such resistant cases are named multidrug-resistant tuberculosis (MDR-TB). ${ }^{1,2}$ The incidence of MDR-TB is increasing worldwide. ${ }^{1,2}$

According to the WHO global tuberculosis report in 2017, the TB incidence rate in Iran was 14 cases per 100,000 populations. ${ }^{3}$ In addition, the overall prevalence of 
TB/HIV co-infection in Iran is $14 \%{ }^{4}$ Although BCG vaccination has been used in Iran as TB control program, but still TB leads to death of about 16,000 Iranian people per year. ${ }^{4,5}$ Despite, $83 \%$ treatment success of TB in Iran, but $23 \%$ of new TB cases and $65.6 \%$ of previously treated persons were resistant to at least one of the first-line drugs. In addition, MDR-TB cases were reported in 5.1\% of new and $33.7 \%$ of retreatment cases. ${ }^{3,6}$

Importantly, the high incidence rate of TB was reported among Afghan immigrants (63.5 per 100,000 in population). ${ }^{7}$ Therefore, migration of Afghan people is one of the significant factors that lead to an increase of TB transmission in Iran.

Although drug-susceptible TB cases can be treated with regular and appropriate therapy within 6 months, treatment of MDR-TB cases is a challenge. The success rates for treatment of MDR-TB are $50 \%$ to $70 \%{ }^{8}$ On the other hand, around $24 \%$ of new emerged MDR-TB cases were not detected in a timely manner. 9,10

Routinely, drug susceptibility testing (DST) of $M$. tuberculosis is performed by the culture-based method which takes several weeks for incubation to yield the results. Hence, rapid, sensitive, and specific methods and techniques are required for diagnosis and DST. ${ }^{9,10}$

The World Health Organization has endorsed rapid molecular tests, such as GeneXpert MTB/RIF and GenoType MTBDRplus VER 2.0, for diagnosis and drug-resistance detection of tuberculosis cases in developed countries. ${ }^{11,12}$ GeneXpert MTB/RIF principle is based on quantitative realtime PCR used by programmatic management of drug-resistant tuberculosis (PMDT) and by Revised National Tuberculosis Control Programs (RNTCP). ${ }^{13}$

GenoType MTBDRplus is a molecular assay able to identify the MTB complex, RIF, and INH-resistant cases simultaneously within a day. ${ }^{9}$ This method also known as line probe assay (LPA) is based on polymerase chain reaction $(\mathrm{PCR})$ and hybridization assay. Specific gene for MTB complex, mutations in $r p o B$ for RIF resistance, kat $G$ for high-level INH resistance, and inhA for low-level INH resistance are detected directly from clinical samples by LPA method. ${ }^{14}$ However, because of strain diversity and various types of mutations in drug-resistant MTB, LPA assay needs to be studied particularly in developing countries.

Although different methods are available for MTB genotyping, mycobacterial interspersed repetitive unitsvariable number tandem repeat (MIRU-VNTR) typing is the most commonly used method. Being rapid, a few amounts of DNA requirement and easy analysis are all the advantages of this technique. ${ }^{15}$

In the present study, the accuracy of LPA assay in detection and drug susceptibility testing of pulmonary TB cases were evaluated and compared with culture and GeneXpert MTB/RIF, irrespective of smear results, in Iran. In addition, phylogenetic analysis and prevalence of gene mutations associated to RIF and INH resistance were evaluated.

\section{Materials And Methods Study Setting And Population}

This study was conducted at the Tehran Regional Reference Laboratory for Tuberculosis affiliated to Tehran University of Medical Sciences. All suspected pulmonary TB cases referred to the center from January to September 2018 were enrolled in the study. Patients with malignancy and extrapulmonary TB were excluded from the study.

\section{Specimens}

This study was a part of routine and standard of care TB investigation at the TB center of Tehran University of Medical Sciences (ethical no. 34623). For sampling, three sputum specimens were obtained from each suspected TB patients in sterile bottles. All sputum specimens were divided into 2 parts, one for GeneXpert/RIF assay and the second was processed by the conventional $\mathrm{N}$-acetyl-L-cysteine $\mathrm{NaOH}$ method ( $1 \%$ final $\mathrm{NaOH}$ concentration). After decontamination, the smears were prepared by Ziehl-Neelsen staining. In addition, sediments were cultured on Löwenstein Jensen medium (LJ) and incubated at $37^{\circ} \mathrm{C}$. Also, DNA extraction was carried out by using Genolyse (Hain Life Sciences, Nehren, Germany) from the leftover sediments according to manufacturer instruction (Figure 1).

\section{Phenotypic Drug Susceptibility Testing}

Drug susceptibility testing was performed using broth microdilution method using U-shaped 96-well microtiter plates. ${ }^{16,17}$ Briefly, wells were filled with $0.1 \mathrm{~mL}$ Middlebrook $7 \mathrm{H} 9$ broth, supplemented with oleic acid, albumin, dextrose, and catalase (OADC) enrichment. The antibiotics, INH, and RIF were serially diluted in wells in different concentrations $(0.03$ to $16 \mu \mathrm{g} / \mathrm{mL}$ ). After that, $5 \mu \mathrm{L}$ of $0.5 \mathrm{McF}$ arland standard bacterial suspension was inoculated into each well. An antibioticfree well was also inoculated with $10^{-2}$ dilution of 0.5 
McFarland standard as positive control, and a well containing pure media was used as negative control. Finally, the plates were sealed, placed in plastic bags, and incubated at $37^{\circ} \mathrm{C}$ for 21 days in a moisturized incubator. In addition, M. tuberculosis H37Rv strain was used as standard.

\section{GeneXpert MTB/RIF Assay}

A total of 920 samples were examined by the GeneXpert MTB/RIF test according to the manufacturer's instruction (Cepheid, Sunnyvale, CA). Briefly, all specimens were treated with sample reagent buffer $(\mathrm{NaOH}$ and isopropanol) and incubated at room temperature for 15 mins. Then, $2 \mathrm{~mL}$ of each specimen was transferred into the GeneXpert MTB/ RIF cartridge and vortexed. Finally, the cartridges were loaded into the GeneXpert machine. The results were generated and recorded after $2 \mathrm{hrs}$ using software version 4.3. ${ }^{18}$

\section{LPA Assay}

LPA assay (Hain Life Sciences, Nehren, Germany) was performed by GenoType MTBDRplus VER 2.0 according to the manufacturer's protocol available at http://www.hainlifescience.de/en/instructions-for-use.html. Briefly, $35 \mu \mathrm{L}$ of a primer-nucleotide mixture (provided with the kit), $10 \mu \mathrm{L}$ of buffer containing Taq DNA polymerase and $\mathrm{MgCl}_{2}$, and $5 \mu \mathrm{L}$ of the extracted DNA (final volume: $50 \mu \mathrm{L}$ ) were used for PCR. The amplification was done in two steps after a 15 -min denaturation at $95^{\circ} \mathrm{C}$, including $30 \mathrm{~s}$ at $95^{\circ} \mathrm{C}$ and $120 \mathrm{~s}$ at $65^{\circ} \mathrm{C}$ for 10 cycles followed by $25 \mathrm{~s}$ at $95^{\circ} \mathrm{C}, 40 \mathrm{~s}$ at $50^{\circ} \mathrm{C}$ and $40 \mathrm{~s}$ at $70^{\circ} \mathrm{C}$ for 30 cycles. The final extension was at $70^{\circ} \mathrm{C}$ for 8 mins. Hybridization and detection were performed using TwinCubator (Hain Life Sciences, Nehren, Germany), according to manufacturer protocol.

\section{Molecular Genotyping}

Total DNA was extracted from the 56 culture positive isolates by standard protocols, as described previously. ${ }^{19}$ Also, 15-locus-based MIRU-VNTR genotyping was performed by specific primers. ${ }^{15}$ Genetic relationships among all isolates were evaluated by the MIRU-VNTRplus software, and finally dendrogram was built according to MIRU-VNTRplus instruction is available at "https:// www.miru-vntrplus.org/MIRU/index.faces". The discrimination cut-off for strains was purposed as 0.17 , according to software default. In this case, the allelic diversity of this method was evaluated by the Hunter-Gaston discriminatory index (HGDI) using free online software at http:// insilico.ehu.es/mini_tools/discriminatory_power/?show= formula. Finally, following formulae been used to calculate the transmission rate of MTB: recent transmission rate $=(\mathrm{TC}-\mathrm{NC}) / \mathrm{TA}$.

According to the transmission rate theory, all patients were classified into two groups, clustered or non-clustered. In this case, when $\mathrm{TB}$ has occurred via recent transmission MTB cases held in the same cluster, in contrast with the reactivation of latent $\mathrm{TB}$ in non-cluster cases. ${ }^{20}$ In this equation, TA is the total number of the studied isolates, TC is the total number of clustered isolates, and NC is the number of clusters.

\section{Data Analysis}

The sensitivity, specificity, positive predictive value (PPV), and negative predictive value (NPV) of LPA results were analyzed by comparing with the solid culture test (LJ culture media) (95\% interval confidence (CI)) using MedCalc-User-friendly statistical software (https://www. medcalc.org/index.php).

\section{Results \\ Comparison Of LPA With GeneXpert And Culture For TB Diagnosis}

From the total of non-duplicated 920 specimens suspected with tuberculosis following results from different techniques were obtained: 5\% (n: 46) were positive in smear microscopy, $6.08 \%$ (n: 56) yielded growth for $M$. tuberculosis complex in culture, 6.8\% (n: 63) produced amplicons by GeneXpert technique, and $6.5 \%$ of patients (n: 60) were diagnosed with tuberculosis by LPA (Table 1).

Compared to culture as a gold standard, the sensitivity, specificity, diagnostic accuracy, PPV, and NPV of LPA for TB detection were $96.5 \%$ (CI: $88.09 \%$ to $99.58 \%$ ), $99.5 \%$ (CI: $98.82 \%$ to $99.87 \%$ ), $93.3 \%$ (CI: $84.03 \%$ to $97.39 \%$ ), and $99.7 \%$ (CI: $99.10 \%$ to $99.94 \%$ ), respectively.

\section{Detection Of MTB Drug-Resistant Cases By LPA In Comparison To GeneXpert And Phenotypic DST}

Phenotype DST and LPA methods confirmed the resistance of 4 and 14 specimens to RIF and INH. These results were also confirmed by GeneXpert method. Mutations in the $r p o B$ gene which were detected by LPA are present in Table 2. Among INH-resistant cases (n: 14), inhA and katG mutations were detected in $14(100 \%)$ and $3(21.4 \%)$ cases, respectively (Figure 2). Two cases had mutations in both the kat $G$ and rрoB genes, which were considered as MDR-TB. In the majority of INH-resistant cases, "A-16G" mutation in inhA 
Table I Comparison Of MTB Detection From Clinical Sputum Specimens By Using Culture, LPA, And GeneXpert Method

\begin{tabular}{|c|c|c|c|}
\hline Case & Culture & LPA & GeneXpert \\
\hline 1 & + & + & + \\
\hline 2 & + & + & + \\
\hline 3 & + & + & + \\
\hline 4 & + & + & + \\
\hline 5 & + & + & + \\
\hline 6 & + & + & + \\
\hline 7 & + & + & + \\
\hline 8 & + & + & + \\
\hline 9 & + & + & + \\
\hline 10 & + & + & + \\
\hline 11 & + & + & + \\
\hline 12 & + & - & + \\
\hline 13 & + & + & + \\
\hline 14 & - & + & + \\
\hline 15 & + & + & + \\
\hline 16 & + & + & + \\
\hline 17 & + & + & + \\
\hline 18 & + & + & + \\
\hline 19 & + & + & + \\
\hline 20 & - & + & + \\
\hline 21 & + & + & + \\
\hline 22 & + & + & + \\
\hline 23 & + & + & + \\
\hline 24 & + & + & + \\
\hline 25 & - & + & + \\
\hline 26 & + & + & + \\
\hline 27 & + & + & + \\
\hline 28 & + & + & + \\
\hline 29 & - & + & + \\
\hline 30 & + & + & + \\
\hline 31 & + & + & + \\
\hline 32 & + & + & + \\
\hline 33 & + & + & + \\
\hline 34 & + & - & + \\
\hline 35 & + & + & + \\
\hline 36 & + & + & + \\
\hline 37 & + & + & + \\
\hline 38 & - & + & + \\
\hline 39 & + & + & + \\
\hline 40 & - & + & + \\
\hline 41 & + & + & + \\
\hline 42 & + & + & + \\
\hline 43 & + & + & + \\
\hline 44 & + & + & + \\
\hline 45 & + & + & + \\
\hline 46 & + & + & + \\
\hline 47 & + & + & + \\
\hline 48 & + & + & + \\
\hline 49 & + & + & + \\
\hline 50 & + & + & + \\
\hline
\end{tabular}

(Continued)
Table I (Continued).

\begin{tabular}{|l|l|l|l|}
\hline Case & Culture & LPA & GeneXpert \\
\hline 51 & + & + & + \\
52 & + & + & + \\
53 & + & + & + \\
54 & + & + & + \\
55 & + & + & + \\
56 & + & + & + \\
57 & + & + & + \\
58 & - & - & + \\
59 & + & + & + \\
60 & + & + & + \\
61 & + & + & + \\
62 & + & + & + \\
63 & + & + & $63(6.8)^{*}$ \\
Total & $56(6.08)^{*}$ & $60(6.5)^{*}$ & \\
\hline
\end{tabular}

Note: *The number and $\%$ of positive results by each method.

Table 2 The Mutation Of rpoB Gene Among RIF-Resistant Strains And Their MICs

\begin{tabular}{|l|l|l|l|}
\hline Isolates & Changed Codon & Mutation & $\begin{array}{l}\text { MICs } \\
(\mu \mathrm{g} / \mathrm{mL})\end{array}$ \\
\hline $\mathrm{I}$ & $\mathbf{5 2 6 - 5 2 9}$ & H526Y & $\mathbf{8}$ \\
2 & $526-529$ & H526Y & 4 \\
3 & $530-533$ & S53IL & 16 \\
4 & $\mathbf{5 0 5 - 5 0 9}$ & $\begin{array}{l}\text { F505L or T508A } \\
\text { or S509T* }\end{array}$ & 32 \\
\hline
\end{tabular}

Notes: Bold: MDR isolate. *Possible mutations for 505-509 region.

gene (85.7\%) was detected. DST results also shown, both lowand high-level resistance to INH. Mutation in inhA (C-15T) gene was detected in 2 cases (14.2\%), correlating with lowlevel resistance to INH (Table 3).

\section{Molecular Genotyping}

According to MIRU-VNTR genotyping results, all 56 culture positive MTB isolates were placed in 29 different clusters (Figure 3). The largest cluster composed 6 isolates followed by 2 clusters with 4 isolates. Also, 3 clusters with 3 isolates and 11 clusters with 2 isolates were reported. The remained 12 remained isolates had with unique patterns which were allocated in unique clusters. The discriminatory power of MIRU-VNTR typing for all isolates was high (HGDI: 0.970). Also, minimum estimate of the proportion of TB occurred among tested population by recent transmission was as $48 \%$. 


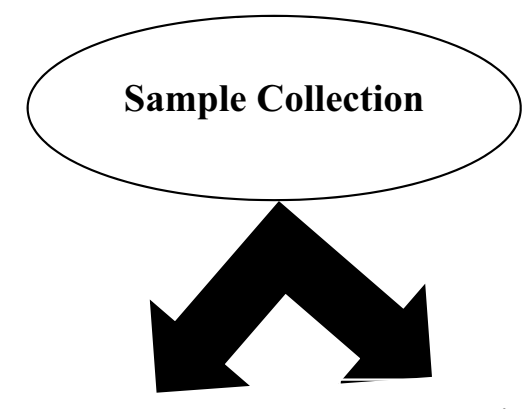

GeneXpert

Decontamination

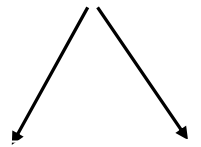

Smear and Culture

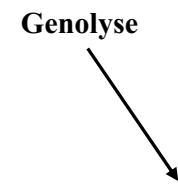

TB Identification

LPA

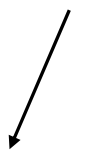

Drug Susceptibly Testing

Figure I Laboratory performance for each pulmonary sample.

\section{Discussion}

The accuracy of LPA method by comparing with the conventional culture and GeneXpert method for tuberculosis detection was evaluated for the first time in Iran. MTB DNA was detected in 6.8\% (n: 63) and 6.5\% (n: 60) of

Table 3 The Mutations Of KatG And inhA Among INH-Resistant Strains And Their MICs

\begin{tabular}{|c|c|c|}
\hline Isolate & Mutation & MICs $(\mu \mathrm{g} / \mathrm{mL})$ \\
\hline I & KatG (S3 I TTI)+InhA (A-I6G) & 8 \\
\hline 2 & KatG (S3I5TI)+InhA (A-I6G) & 16 \\
\hline 3 & KatG (S3I5TI)+InhA (A-I6G) & 4 \\
\hline 4 & $\operatorname{Inh} A(A-16 G)$ & 4 \\
\hline 5 & $\operatorname{Inh} A(A-16 G)$ & 2 \\
\hline 6 & $\operatorname{Inh} A(A-16 G)$ & 4 \\
\hline 7 & $\operatorname{Inh} A(A-16 G)$ & 0.125 \\
\hline 8 & $\operatorname{Inh} A(A-16 G)$ & I \\
\hline 9 & $\operatorname{Inh} A(\mathrm{~A}-16 \mathrm{G})$ & 4 \\
\hline 10 & $\operatorname{Inh} A(A-16 G)$ & I \\
\hline 11 & $\operatorname{Inh} A(A-16 G)$ & 0.5 \\
\hline 12 & $\operatorname{Inh} A(A-16 G)$ & 2 \\
\hline 13 & $\operatorname{Inh} A(C-15 T)$ & 0.125 \\
\hline 14 & $\operatorname{Inh} A(C-15 T)$ & 0.125 \\
\hline
\end{tabular}

Note: Bold: MDR isolate.

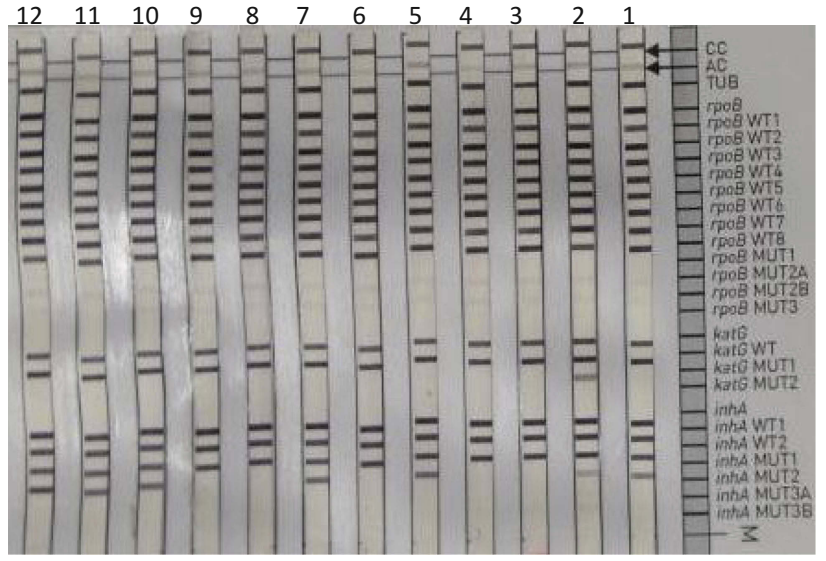

Figure 2 Banding patterns obtained by GenoType MTBDRplus VER 2.0 test. CC; conjugate control, AC; amplification control, TUB; $M$. tuberculosis complex-specific control, rpoB, kat $G$ and inhA; locus control zones specific for each gene. (Sample 8 is positive control of MTB ( $\mathrm{H} 37 \mathrm{Rv}$ ), sample 2 have katG WT (wild type) and katG MUTI bands which show S3I5TI mutation in codon 315 of katG gene; Samples I, 2, $5,7,10,11$, and 12 have inh WTI, 2 and inhA MUTI bands which show A-I6G mutation in inhA gene. Sample 2 has both KatG (S3I5TI) and inhA (A-I6G) mutations simultaneously.

clinical specimens by using GeneXpert MTB/RIF and LPA methods, respectively. Importantly, 6.08\% (n: 56) of clinical specimens were grown on culture media. Although positive results been obtained by both GeneXpertMTB/ RIF and LPA methods but cultured based method shown negative results. The detection of dead bacilli by molecular technique may have resulted to false positive results. Hence, when a new test is assayed against culturing method as a reference standard, it can show false positive results. ${ }^{14,21}$ Two cases were reported as false negative by LPA method, which these cases were reported "very low" by GeneXpert MTB/RIF and were grown in culture. This result is probably due to detection limit of LPA, which is more than culture and GeneXpert MTB/RIF. ${ }^{21}$ Therefore, low bacillary load specimen may lead to miss detection of TB by LPA.

Results obtained in this study show high and significant sensitivity specificity, PPV, and NPV of LPA in comparison of cultured method. A study conducted in South Africa $(\mathrm{n}=282)$ reported sensitivity of $73.1 \%$ and specificity of $100 \%$ for detection of MTB. ${ }^{22}$ In compare to our study, it seems lower LPA efficacy in South Africa may arise from coinfection of TB with HIV. According to global information and education on HIV and AIDS report, HIV prevalence is high among the general population of South Africa at $20.4 \%$. Also, HIV patients have higher rates of sputum smear-negative TB. On the other hand, LPA is recommended for acid fast bacilli (AFB) smear-positive sputum because 


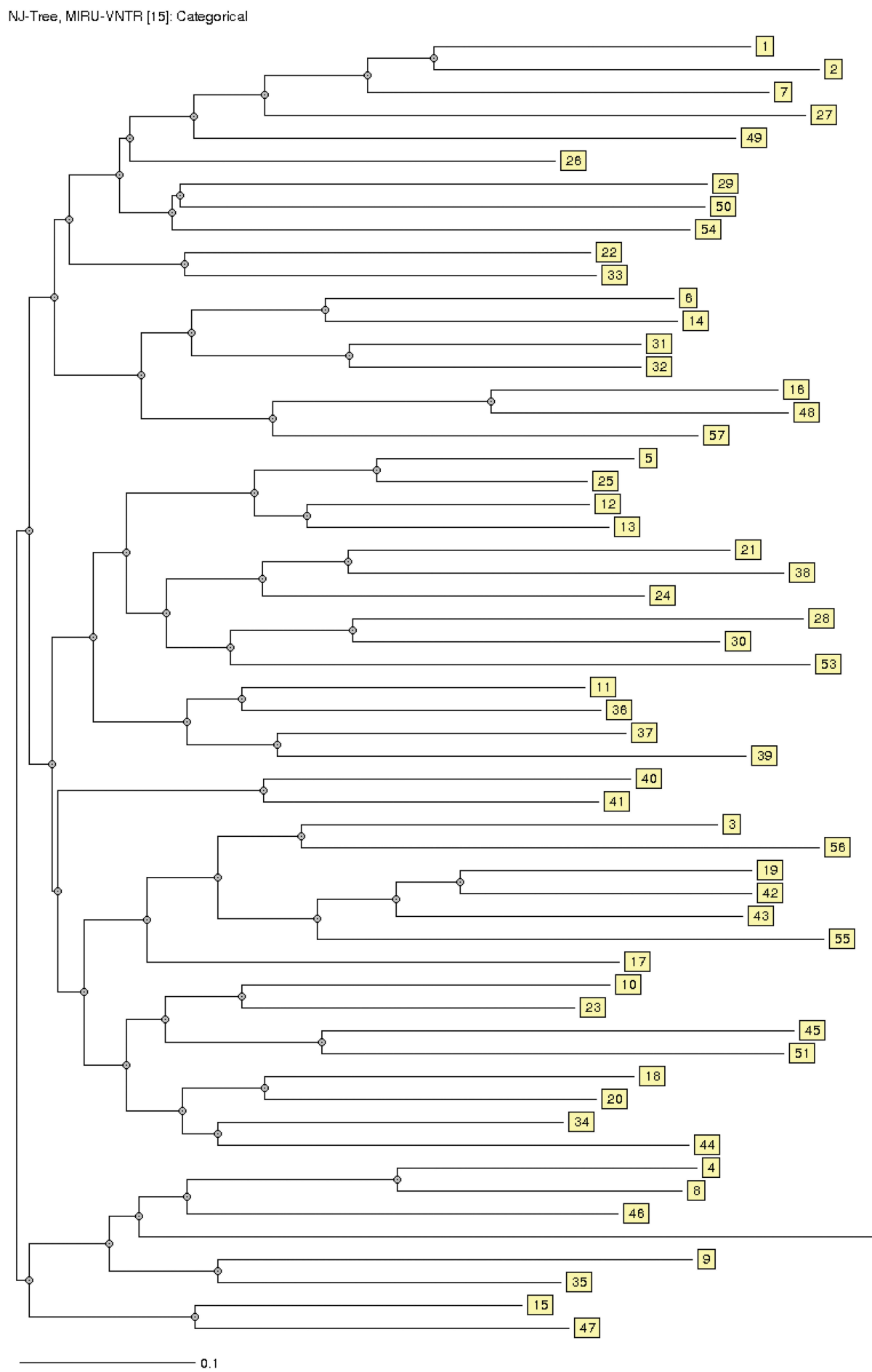

$\begin{array}{lllllllllllllll}3 & 4 & 3 & 1 & 3 & 2 & 2 & 5 & 3 & 2 & 3 & 3 & 5 & 5 & 2\end{array}$ $\begin{array}{lllllllllllllll}2 & 4 & 2 & 1 & 3 & 2 & 0 & 2 & 3 & 3 & 2 & 3 & 5 & 5 & 2\end{array}$ $\begin{array}{lllllllllllllll}3 & 4 & 2 & 1 & 4 & 2 & 2 & 4 & 4 & 3 & 5 & 4 & 5 & 5 & 2\end{array}$ $\begin{array}{lllllllllllllll}5 & 4 & 2 & 3 & 0 & 1 & 0 & 4 & 0 & 3 & 3 & 3 & 5 & 3 & 2\end{array}$ $\begin{array}{lllllllllllllll}5 & 3 & 3 & 1 & 3 & 1 & 7 & 4 & 3 & 3 & 5 & 4 & 3 & 8 & 2\end{array}$ $\begin{array}{lllllllllllllll}3 & 4 & 3 & 3 & 0 & 0 & 2 & 2 & 3 & 3 & 0 & 4 & 3 & 5 & 2\end{array}$ $\begin{array}{lllllllllllllll}5 & 4 & 3 & 2 & 0 & 4 & 7 & 3 & 6 & 2 & 7 & 5 & 3 & 6 & 2\end{array}$ $\begin{array}{lllllllllllllll}1 & 4 & 3 & 3 & 2 & 0 & 7 & 4 & 3 & 2 & 6 & 3 & 4 & 6 & 2\end{array}$ $\begin{array}{lllllllllllllll}3 & 3 & 3 & 5 & 0 & 4 & 2 & 5 & 3 & 2 & 6 & 3 & 3 & 8 & 2\end{array}$ $\begin{array}{llllllllllllllll}2 & 4 & 3 & 3 & 6 & 4 & 2 & 2 & 2 & 3 & 7 & 3 & 2 & 8 & 2\end{array}$ $\begin{array}{lllllllllllllll}4 & 4 & 3 & 3 & 3 & 3 & 3 & 2 & 3 & 5 & 1 & 3 & 2 & 8 & 2\end{array}$ $\begin{array}{lllllllllllllll}3 & 4 & 2 & 1 & 5 & 3 & 5 & 2 & 2 & 3 & 6 & 4 & 4 & 3 & 2\end{array}$ $\begin{array}{lllllllllllllll}3 & 4 & 3 & 1 & 5 & 2 & 2 & 2 & 2 & 2 & 4 & 4 & 4 & 5 & 2\end{array}$ $\begin{array}{lllllllllllllll}3 & 4 & 3 & 4 & 5 & 4 & 3 & 2 & 0 & 2 & 5 & 3 & 1 & 5 & 2\end{array}$ $\begin{array}{lllllllllllllll}3 & 4 & 3 & 4 & 1 & 4 & 3 & 2 & 2 & 2 & 4 & 3 & 4 & 6 & 2\end{array}$ $\begin{array}{lllllllllllllll}3 & 3 & 3 & 1 & 4 & 1 & 2 & 2 & 2 & 2 & 5 & 0 & 2 & 6 & 3\end{array}$ $\begin{array}{lllllllllllllll}3 & 3 & 2 & 1 & 4 & 3 & 2 & 2 & 2 & 2 & 5 & 6 & 4 & 7 & 3\end{array}$ $\begin{array}{lllllllllllllll}1 & 4 & 2 & 3 & 4 & 3 & 6 & 2 & 2 & 2 & 5 & 6 & 5 & 7 & 2\end{array}$ $\begin{array}{lllllllllllllll}4 & 4 & 2 & 3 & 4 & 4 & 5 & 5 & 5 & 4 & 5 & 5 & 3 & 8 & 2\end{array}$ $\begin{array}{lllllllllllllll}1 & 4 & 3 & 3 & 5 & 4 & 5 & 5 & 5 & 5 & 5 & 5 & 3 & 8 & 2\end{array}$ $\begin{array}{lllllllllllllll}3 & 4 & 3 & 3 & 4 & 2 & 5 & 6 & 5 & 4 & 5 & 7 & 3 & 8 & 2\end{array}$ $\begin{array}{lllllllllllllll}5 & 4 & 3 & 3 & 4 & 3 & 5 & 2 & 5 & 4 & 5 & 8 & 5 & 8 & 2\end{array}$ $\begin{array}{lllllllllllllll}3 & 4 & 3 & 1 & 6 & 2 & 4 & 5 & 5 & 5 & 6 & 4 & 4 & 6 & 3\end{array}$ $\begin{array}{lllllllllllllll}4 & 4 & 3 & 4 & 7 & 1 & 4 & 5 & 5 & 5 & 8 & 5 & 4 & 6 & 2\end{array}$ $\begin{array}{lllllllllllllll}3 & 4 & 3 & 3 & 4 & 0 & 3 & 5 & 5 & 5 & 5 & 5 & 4 & 9 & 2\end{array}$ $\begin{array}{lllllllllllllll}3 & 2 & 5 & 3 & 1 & 4 & 5 & 5 & 5 & 5 & 3 & 5 & 4 & 8 & 3\end{array}$ $\begin{array}{lllllllllllllll}3 & 4 & 3 & 3 & 1 & 4 & 5 & 3 & 5 & 5 & 6 & 5 & 2 & 5 & 0\end{array}$ $\begin{array}{lllllllllllllll}3 & 2 & 2 & 3 & 6 & 6 & 1 & 6 & 5 & 5 & 4 & 4 & 3 & 5 & 3\end{array}$ $\begin{array}{lllllllllllllll}5 & 4 & 3 & 3 & 4 & 3 & 5 & 6 & 2 & 3 & 6 & 5 & 3 & 7 & 2\end{array}$ $\begin{array}{lllllllllllllll}5 & 4 & 3 & 3 & 8 & 3 & 2 & 4 & 4 & 5 & 6 & 4 & 3 & 7 & 2\end{array}$ $\begin{array}{lllllllllllllll}5 & 4 & 3 & 3 & 8 & 3 & 5 & 2 & 0 & 5 & 6 & 6 & 3 & 8 & 3\end{array}$ $\begin{array}{lllllllllllllll}2 & 3 & 3 & 3 & 2 & 0 & 5 & 5 & 5 & 5 & 6 & 6 & 3 & 7 & 3\end{array}$ $\begin{array}{lllllllllllllll}3 & 2 & 3 & 3 & 7 & 3 & 4 & 2 & 2 & 5 & 9 & 6 & 3 & 4 & 2\end{array}$ $\begin{array}{llllllllllllll}1 & 2 & 3 & 3 & 6 & 3 & 4 & 2 & 2 & 4 & 105 & 3 & 3 & 2\end{array}$ $\begin{array}{lllllllllllllll}4 & 2 & 2 & 3 & 5 & 3 & 4 & 2 & 5 & 3 & 7 & 6 & 3 & 8 & 3\end{array}$ $\begin{array}{lllllllllllllll}5 & 2 & 2 & 2 & 5 & 3 & 3 & 2 & 2 & 3 & 5 & 5 & 4 & 7 & 3\end{array}$ $\begin{array}{lllllllllllllll}2 & 2 & 3 & 4 & 5 & 4 & 0 & 5 & 3 & 5 & 6 & 3 & 3 & 8 & 3\end{array}$ $\begin{array}{lllllllllllllll}2 & 2 & 2 & 4 & 5 & 4 & 5 & 2 & 3 & 3 & 7 & 3 & 3 & 8 & 3\end{array}$ $\begin{array}{lllllllllllllll}4 & 2 & 3 & 4 & 5 & 4 & 5 & 2 & 0 & 3 & 1 & 3 & 3 & 2 & 3\end{array}$ $\begin{array}{lllllllllllllll}5 & 2 & 3 & 4 & 5 & 4 & 2 & 3 & 3 & 3 & 4 & 5 & 2 & 4 & 3\end{array}$ $\begin{array}{lllllllllllllll}4 & 3 & 3 & 3 & 6 & 5 & 3 & 2 & 3 & 3 & 5 & 5 & 3 & 6 & 3\end{array}$ $\begin{array}{lllllllllllllll}3 & 4 & 3 & 3 & 6 & 6 & 4 & 2 & 5 & 4 & 1 & 5 & 3 & 3 & 1\end{array}$ $\begin{array}{lllllllllllllll}1 & 4 & 3 & 3 & 6 & 1 & 3 & 2 & 5 & 4 & 7 & 5 & 3 & 8 & 3\end{array}$ $\begin{array}{lllllllllllllll}4 & 4 & 3 & 3 & 6 & 2 & 3 & 3 & 1 & 4 & 3 & 3 & 5 & 6 & 1\end{array}$ $\begin{array}{lllllllllllllll}2 & 4 & 3 & 3 & 2 & 0 & 4 & 6 & 5 & 4 & 3 & 8 & 5 & 6 & 3\end{array}$ $\begin{array}{lllllllllllllll}2 & 5 & 3 & 3 & 6 & 4 & 3 & 2 & 4 & 4 & 6 & 3 & 3 & 7 & 3\end{array}$ $\begin{array}{lllllllllllllll}3 & 2 & 3 & 3 & 5 & 4 & 4 & 2 & 3 & 4 & 6 & 4 & 3 & 7 & 3\end{array}$ $\begin{array}{lllllllllllllll}5 & 4 & 3 & 3 & 2 & 4 & 5 & 2 & 4 & 4 & 5 & 4 & 3 & 8 & 3\end{array}$ $\begin{array}{lllllllllllllll}2 & 4 & 3 & 3 & 8 & 2 & 4 & 2 & 4 & 4 & 7 & 4 & 4 & 4 & 3\end{array}$ $\begin{array}{lllllllllllllll}2 & 4 & 2 & 4 & 3 & 3 & 5 & 3 & 0 & 3 & 5 & 5 & 3 & 8 & 2\end{array}$ $\begin{array}{lllllllllllllll}3 & 4 & 1 & 4 & 3 & 3 & 5 & 3 & 4 & 3 & 5 & 4 & 3 & 7 & 2\end{array}$ $\begin{array}{lllllllllllllll}3 & 4 & 1 & 3 & 6 & 3 & 3 & 3 & 4 & 2 & 3 & 5 & 3 & 3 & 2\end{array}$ $\begin{array}{llllllllllllllll}52 & 4 & 3 & 1 & 2 & 8 & 3 & 4 & 6 & 4 & 4 & 8 & 4 & 1 & 3 & 2\end{array}$ $\begin{array}{lllllllllllllll}3 & 5 & 1 & 3 & 4 & 2 & 3 & 3 & 5 & 4 & 1 & 4 & 3 & 3 & 3\end{array}$ $\begin{array}{lllllllllllllll}3 & 4 & 3 & 4 & 4 & 4 & 3 & 3 & 3 & 4 & 7 & 4 & 3 & 3 & 2\end{array}$ $\begin{array}{lllllllllllllll}3 & 1 & 3 & 3 & 4 & 4 & 3 & 2 & 5 & 3 & 6 & 8 & 3 & 1 & 2\end{array}$ $\begin{array}{lllllllllllllll}3 & 3 & 3 & 2 & 4 & 4 & 3 & 2 & 4 & 3 & 1 & 3 & 3 & 7 & 2\end{array}$

Figure 3 Genetic relatedness of 53 M. tuberculosis isolates by MIRU-VNTR genotyping ( 0.17 cut-off). Right hand: the allele number of I5 loci in MIRU-VNTR for each isolate. Isolate $\mathrm{I}$ is $M$. tuberculosis H37Rv.

of its detection limit. Therefore, LPA is more suitable for our setting. ${ }^{23,24}$ Another study was conducted in India on smear-positive samples and reported that LPA had $100 \%$ concordance with TB detection by culture method. ${ }^{25}$
All the cases that were detected by LPA as MTB were also detected by GeneXpert MTB/RIF molecular method. Only three cases were not detected by LPA which were detected by GeneXpert MTB/RIF method as MTB. All the four RIF-resistant cases were detected by both LPA and 
GeneXpert MTB/RIF molecular method as well as phenotypical DST. All the 4 rров mutations were concordances with the MICs results as high-level RIF resistant (Table 2). According to the LPA and DST results, two cases were considered as MDR-TB (3.1\%). The MDR-TB cases were isolated from Iranian and Afghan migrant patients with treatment failure. These cases had unique patterns in the MIRU-VNTR molecular typing method (isolates 52 and 17 in dendrogram).

Our data revealed that 2 cases $(3.1 \%)$ were RIF monoresistant with a unique pattern in MIRU-VNTR genotyping. One of these cases was isolated as relapse from an Iranian patient and another was isolated from an Afghan migrant as a primary diagnosis (isolates 46 and 15 in dendrogram). The incidence of RIF mono-resistance varies from region to region or country to country. For instance, high rates were reported from South Africa, in association with HIV patients, whereas RIF mono-resistance rates commonly vary from $0.1 \%$ to $3 \%{ }^{14}$

Among TB cases, 14 cases (22.2\%) were identified as INH-resistant using LPA and DST. Among INH-resistant cases, 2 cases (14.2\%) were reported as MDR-TB and 12 cases $(85.7 \%)$ as INH mono-resistant. Only 1 kat G mutation (S315T1) was reported in INH mono-resistant cases, whereas inhA mutations were detected in 12 INH monoresistant and two MDR cases (Table 3). According to molecular typing analysis, 2 INH mono-resistant cases, with $\mathrm{MIC}=4 \mu \mathrm{g} / \mathrm{mL}$, were placed in 1 cluster. Both cases were isolated from Afghan migrant patients. Interestingly, the first patient was considered as relapse and the second as primary diagnosis. Both of them were living in south of Tehran. Perhaps, strain transmission was happened during migration or later (isolates 4 and 8 in dendrogram). Also, transmission rate estimation showed a high percent of recent transmission among tested case as $48 \%$.

Eight INH mono-resistant cases were placed in a unique cluster, which they were isolated from treatment failure, relapse, and treatment control of Iranian and Afghan migrant patients (isolates 22, 26, 29, 33, 47, 49, 50 , and 54 in dendrogram). Two INH mono-resistant (isolates 11and 31) were isolated from Iranian relapsed TB patients. These cases were placed in different clusters. The molecular typing method confirmed that INH resistance in these two cases were happened in the patients' bodies during infection and unsuccessful treatment, because other members of their cluster were INH-sensitive.

According to published data, higher prevalence of $k a t G$ mutation among INH-resistant cases were reported from
Russia (95\%), Brazil (81.3\%), Peru (82.4\%), Argentina (71.4\%), Kuwait (65\%), and the Netherlands (55\%). ${ }^{23}$ Their analysis showed that the prevalence of inhA mutation among INH-resistant cases is variable (15-35\%) and is dependent on geographical region. ${ }^{26}$ Notably, inhA mutations are more common in South-East Asian immigrants; also, $40 \%$ of MDR-TB isolates from Eastern Capes of South Africa have inhA mutation without concurrent $k a t G$ mutation. ${ }^{27,28}$

The inhA mutations were found in all INH mono-resistant and MDR-TB cases. In MDR-TB cases and 1 INH monoresistant case, both inhA and $k a t G$ mutation were coexisted. However, these data showed that shifting occurred in the genotype of INH-resistant cases - especially in INH monoresistant cases in our region. The present study was the first report on the high prevalence of inhA mutation among TB cases in Iran. Recently, a study was published in India, which reported high prevalence of inhA mutation among MDR and INH mono-resistant TB cases. ${ }^{29}$ According to their report, $42 \%$ of MDR cases and $62.5 \%$ of INH mono-resistant cases had inhA mutation. This shifting may be due to the increased clonality of TB cases from transmitted strains. It has been shown that TB strain diversity decreases when drug-resistance is increasing. ${ }^{30}$

It has been reported that the most common inhA mutations are frequently associated with INH mono-resistance ${ }^{31}$ and confers low-level INH resistance in MTB strains. ${ }^{32,33}$ However, our data indicated that inhA mutations could confer both high- and low-level INH resistance in MTB cases (Table 3). Notably, low-level resistance suggests that the minimum inhibitory concentration is higher than in a susceptible population of tested bacteria, leading to failure in therapy. Therefore, it acts as a prognosis for MDR-TB case that can be easily detected by LPA. ${ }^{34}$

LPA is a rapid method compared to other methods such as culturing and DST. Also, its advantage is identifying the mono-resistant mutants of RIF and INH. On the other hand, LPA is the best test for isolates with borderline RIF and INH resistance and able to detect the presence of hetero-resistance cases. ${ }^{35}$ For example, MICs of INH in 3 cases were in borderline range. This phenomenon sometimes is problematic especially when the clinician is waiting for laboratory report to start the therapy. But, if DST results are confirmed by LPA assay, problem of doubtable results can be solved easily.

\section{Conclusion}

In conclusion, for accurate diagnosis of TB and MDR-TB cases, identifying the nature of mutations is needed for appropriate treatment. LPA assay is a rapid, reliable, and in-house 
method to analyze the simultaneous detection of TB and its drug resistance, which leads to early diagnosis and appropriate drug therapy. High prevalence of inh $A$ mutations were detected by LPA among our patients and also circulating of these cases were shown among population. So, LPA results may allow clinicians to adjust a patient's regimen and maximize its effectiveness in Iran. This study has shown that LPA is the appropriate method for early detection of TB and drug-resistant TB cases in Iran.

\section{Data Accessibility}

All data are included in the manuscript.

\section{Acknowledgment}

This study was supported by Tehran University of Medical Sciences (project no. 34623).

\section{Author Contributions}

All authors made substantial contributions to conception and design, acquisition of data, or analysis and interpretation of data; took part in drafting the article or revising it critically for important intellectual content; gave final approval of the version to be published; and agree to be accountable for all aspects of the work.

\section{Disclosure}

The authors report no conflicts of interest in this work.

\section{References}

1. Yamchi JK, Haeili M, Feyisa SG, et al. Evaluation of efflux pump gene expression among drug susceptible and drug-resistant strains of Mycobacterium tuberculosis from Iran. Infect Genet Evol. 2015;36:23-26. doi:10.1016/j.meegid.2015.08.036

2. Kazemian H, Haeili M, Yamchi JK, et al. Antimycobacterial activity of linezolid against multidrug-resistant and extensively drug-resistant strains of Mycobacterium tuberculosis in Iran. Int $J$ Antimicrob Agents. 2015;45:668-670. doi:10.1016/j.ijantimicag.2015.02.004

3. World Health Organization (WHO). Global tuberculosis report 2017. Available from: www.who.int/tb/publications/global_report/. Accessed October 31, 2019.

4. Pourakbari B, Mamishi S, Banar M, Keshtkar AA, Mahmoudi S. Prevalence of TB/HIV co-infection in Iran: a systematic review and meta-analysis. Ann Ig. 2019;31(4):333-348. doi:10.7416/ai.2019.2295

5. Kazemian H, Kardan-Yamchi J, Mosavari N, Feizabadi MM. Molecular characterization of multidrug and extensive drug-resistant Mycobacterium tuberculosis isolates from Iran. Infez Med. 2019;27(1):26-31.

6. Nasiri MJ, Dabiri H, Darban-Sarokhalil D, Rezadehbashi M, Zamani S. Prevalence of drug-resistant tuberculosis in Iran: systematic review and meta-analysis. Am J Infect Control. 2014;42(11):1212-1218. doi:10.1016/j.ajic.2014.07.017

7. Kadivar MR, Ghaneh-Shirazi R, Khavandegaran F, Karimi M. Epidemiology of tuberculosis among Afghan immigrants in Fars province, southern Islamic Republic of Iran. East Mediterr Health J. 2007;13(4):758-764.
8. Zignol M, Gemert WV, Falzon D, et al. Surveillance of anti-tuberculosis drug resistance in the world: an updated analysis, 2007-2010. Bull World Health Organ. 2012;90:111-119. doi:10.2471/BLT.11.092585

9. Hillemann D, Rüsch-Gerdes S, Richter E. Evaluation of the GenoTypeMTBDRplus assay for rifampin and isoniazid susceptibility testing of Mycobacterium tuberculosis strains and clinical specimens. J Clin Microbiol. 2007;45:2635-2640.

10. Falzon D, Jaramillo E, Schünemann HJ, et al. WHO guidelines for the programmatic management of drug-resistant tuberculosis: 2011 update. EurRespir J. 2011;38:516-528. doi:10.1183/09031936.00073611

11. World Health Organization. Molecular line probe assays for rapid screening of patients at risk of multidrug-resistant tuberculosis (MDR-TB). Policy Statement. 2008;27.

12. World Health Organization. Rapid Implementation of the Xpert ${ }^{\circledR}$ MTB/RIF Diagnostic Test: Technical, Operational 'howto' and Practical Considerations. Geneva, Switzerland: WHO; 2011.

13. Jaramillo E. Guidelines for the Programmatic Management of DrugResistant Tuberculosis. World Health Organization; 2008.

14. Ninan MM, Gowri M, Christopher DJ, Rupali P, Michael JS. The diagnostic utility of line probe assays for multidrug-resistant tuberculosis. Pathog Glob Health. 2016;110:194-199. doi:10.1080/ 20477724.2016.1214350

15. Zamani S, Aflaki M, Fooladi AA, et al. MIRU-VNTR analysis of the Mycobacterium tuberculosis isolates from three provinces of Iran. Scand $J$ Infect Dis. 2013;45:124-130. doi:10.3109/00365548.2012.717233

16. Leite CQ, Beretta AL, Anno IS, Telles MA. Standardization of broth microdilution method for Mycobacterium tuberculosis. Mem Inst Oswaldo Cruz. 2000;95:127-129. doi:10.1590/S0074-02762000000100021

17. Kazemian H, Heidari H, Yamchi JK, et al. al. In vitro anti-mycobacterial activity of three medicinal plants of Lamiaceae family. Recent Pat Antiinfect Drug Discov. 2018;26:1-8.

18. Boehme CC, Nabeta P, Hillemann D, et al. Rapid molecular detection of tuberculosis and rifampin resistance. $N$ Engl $J$ Med. 2010;363:1005-1015. doi:10.1056/NEJMoa0907847

19. Van Helden PD, Victor TC, Warren RM, Van Helden EG. Isolation of DNA from Mycobacterium tuberculosis. Methods Mol Med. 2001;54:19-30. doi:10.1385/1-59259-147-7:019

20. Small PM, Hopewell PC, Singh SP, et al. The epidemiology of tuberculosis in San Francisco. A population-based study using conventional and molecular methods. N Engl J Med. 1994;330:17031709. doi:10.1056/NEJM199406163302402

21. Crudu V, Stratan E, Romancenco E, Allerheiligen V, Hillemann A, Moraru N. First evaluation of an improved assay for molecular genetic detection of tuberculosis as well as RMP and INH resistances. J Clin Microbiol. 2012;50:1264-1269.

22. Barnard M, van Pittius NG, Van Helden PD, Bosman M, Coetzee G, Warren RM. Diagnostic performance of Genotype ${ }^{\circledR}$ MTBDRplus Version 2 line probe assay is equivalent to the Xpert@ MTB/RIF assay. J Clin Microbiol. 2012;50:3712-3716.

23. Hassim S, Shaw PA, Sangweni P, et al. Detection of a substantial rate of multidrug-resistant tuberculosis in an HIV-infected population in South Africa by active monitoring of sputum samples. Clin Infect Dis. 2010;50:1053-1059. doi:10.1086/649514

24. Desikan P, Panwalkar N, Mirza SB, et al. Line probe assay for detection of Mycobacterium tuberculosis complex: an experience from Central India. Indian $J$ Med Res. 2017;145:70-73. doi:10.4103/ijmr.IJMR_831_14

25. Rufai SB, Kumar P, Singh A, Prajapati S, Balooni V, Singh S. Comparison of Xpert MTB/RIF with Line Probe Assay for detection of Rifampicin monoresistant Mycobacterium tuberculosis. J Clin Microbiol. 2014;52:1846-1852.

26. Brossier F, Veziris N, Truffot-Pernot C, Jarlier V, Sougakoff W. Performance of the genotype MTBDR line probe assay for detection of resistance to rifampin and isoniazid in strains of Mycobacterium tuberculosis with low-and high-level resistance. J Clin Microbiol. 2006;44:3659-3664. 
27. Varghese B, Shoukri M, Memish Z, et al. Occurrence of Diverse Mutations in Isoniazid- and Rifampicin-Resistant Mycobacterium tuberculosis Isolates from Autochthonous and Immigrant Populations of Saudi Arabia. Microb Drug Resist. 2014;20:623631. doi:10.1089/mdr.2014.0065

28. Muller B, Streicher EM, Hoek KG, et al. inhA promoter mutations: a gateway to extensively drug-resistant tuberculosis in South Africa? Int J Tuberc Lung Dis. 2011;15:344-351.

29. Shenoy VP, Kumar A, Chawla K. Rapid detection of multidrugresistant tuberculosis in respiratory specimens at a tertiary care centre in south coastal Karnataka using Genotype MTBDR plus assay. Iran $J$ Microbiol. 2018;10:275-280.

30. Gandhi NR, Brust JC, Moodley P, et al. Minimal diversity of drugresistant Mycobacterium tuberculosis strains, South Africa. Emerg Infect Dis. 2014;20:426-433. doi:10.3201/eid2003.131083

31. Almeida Da Silva PE, Palomino JC. Molecular basis and mechanisms of drug resistance in Mycobacterium tuberculosis: classical and new drugs. J Antimicrob Chemother. 2011;66:1417-1430. doi:10.1093/jac/dkr173
32. Gillespie SH. Evolution of drug resistance in Mycobacterium tuberculosis: clinical and molecular perspective. Antimicrob Agents Chemother. 2002;46:267-274. doi:10.1128/AAC.46.2.267274.2002

33. Jiao WW, Mokrousov I, Sun GZ, et al. Molecular characteristics of rifampin and isoniazid resistant Mycobacterium tuberculosis strains from Beijing, China. Chin Med J (Engl). 2007;120:814-819 doi:10.1097/00029330-200705010-00014

34. LPA Laboratory Manual. Find diagnostics. March 2012 [Internet] [cited June 23, 2014]. Availablefrom: http://www.finddiagnostics. org/export/sites/default/resourcecentre/reports_brochures/docs/LPA LaboratoryManual 22Mar2012.pdf. Accessed October 31, 2019.

35. Mekonnen D, Admassu A, Mulu W, et al. Multidrug-resistant and heteroresistant Mycobacterium tuberculosis and associated gene mutations in Ethiopia. Int J Infect Dis. 2015;39:34-38. doi:10.1016/ j.ijid.2015.06.013
Infection and Drug Resistance

\section{Publish your work in this journal}

Infection and Drug Resistance is an international, peer-reviewed openaccess journal that focuses on the optimal treatment of infection (bacterial, fungal and viral) and the development and institution of preventive strategies to minimize the development and spread of resistance. The journal is specifically concerned with the epidemiology of
Dovepress

antibiotic resistance and the mechanisms of resistance development and diffusion in both hospitals and the community. The manuscript management system is completely online and includes a very quick and fair peerreview system, which is all easy to use. Visit http://www.dovepress.com/ testimonials.php to read real quotes from published authors. 